\title{
Factors associated with minimal meal frequency and dietary diversity practices among infants and young children in the predominantly agrarian society of Bale zone, Southeast Ethiopia: a community based cross sectional study
}

\author{
Mekonnen Tegegne ${ }^{1}$, Semere Sileshi ${ }^{2}$, Tomas Benti ${ }^{1}$, Mulusew Teshome ${ }^{2}$ and Haile Woldie ${ }^{3^{*}}$
}

\begin{abstract}
Background: Poor infant and young child feeding (IYCF) practices in the first 2 years of age are among major causes of childhood malnutrition, in developing countries including Ethiopia. It results in irreversible outcomes of stunting, poor cognitive development, and significantly increases risks of many chronic and infectious diseases. This study was intended to assess factors associated with minimum meal frequency and minimum dietary diversity practice among children aged 6-23 months in the predominantly agrarian society of Bale zone, Southeast Ethiopia.

Methods: A community based cross sectional study was employed from January to June 2016. An interviewer administered, pretested and structured questionnaire was used to collect data. Multi-stage sampling followed by a systematic random sampling technique was used to include study subjects. Data was entered using Epi info version 3.5.3 and analyzed by SPSS version 20. In the logistic regression, both bivariate and multivariate analyses were carried out to identify factors associated with minimum meal frequency and minimum dietary diversity scores. All variables with $P$-values of $<0.2$ in the bivariate were earmarked for the multivariate analysis. Both Crude Odds Ratio (COR) and Adjusted Odds Ratio (AOR) were computed at 95\% Confidence Interval (Cl) to determine the strength of associations. In the multivariate analysis, variables at P-Values of $<0.05$ were considered as statistically significant with minimum meal frequency and dietary diversity practice.

Result: A total of 801 infants and young children aged 6-23 months and their mothers participated in the study. The overall prevalence of minimum meal frequency and minimum dietary diversity practice was $68.4 \%$ [95\% Cl: 0.652 , $0.716]$ and $28.5 \%$ [95\% Cl: $0.254,0.316]$, respectively. Child age ( $\mathrm{AOR}=0.29 ; 95 \% \mathrm{Cl}: 0.28,0.94$ ) and parity of mother $(A O R=2.8 ; 95 \% \mathrm{Cl}: 1.11,7.50)$ were independently associated with minimal meal frequency. On the other hand, mothers educational level (AOR $=0.52 ; 95 \% \mathrm{Cl}: 0.28,0.94)$, child illness in the past 1 week (AOR $=0.44 ; 95 \% \mathrm{Cl}: 0.26,0$. 73) and maternal counselling on IYCF practice during postnatal care (PNC) visits (AOR $=2.6 ; 95 \% \mathrm{Cl}: 1.59,4.45)$ were factors statistically associated with dietary diversity practice in the study area.

(Continued on next page)
\end{abstract}

\footnotetext{
* Correspondence: yalewhaile28@gmail.com

${ }^{3}$ Department of Human Nutrition, Institute of Public Health, College of

Medicine and Health Sciences, University of Gondar, Gondar, Ethiopia

Full list of author information is available at the end of the article
} 
(Continued from previous page)

Conclusion and recommendations: Compliance to recommended minimum meal frequency and diversified diets was low in this study community. Minimum meal frequency was associated with the age of child and parity of mother. But, mothers' education, child illness in the past 1 week, and maternal counseling on IYCF during PNC visits were factors associated with minimum dietary diversity practice. Improving the level of maternal and child health care utilization, increasing the educational level of mothers and providing health and nutrition counseling on IYCF during maternal PNC service visits are vital interventions to improve IYCF practices in the predominantly agrarian society of Bale zone, Southeast Ethiopia.

Keywords: Aged 6-23 months, Meal frequency, Dietary diversity, Associated factors

\section{Background}

Appropriate feeding practices in the first 2 years of age are important measures to meet nutritional requirements [1] and improve physical growth and cognitive development [2]. The most recent preliminary results showed that improper IYCF practices in this windows period are among the major causes of childhood malnutrition [3] resulting in permanent outcomes of stunting, poor cognitive development, and significantly increases risks of many chronic and infectious diseases [4-6]. The potential negative impact of malnutrition during this critical period is not limited to childhood life [7] rather it diminishes individual level of productivity during adulthood [8], negatively affecting the future social and economic development of countries [9] and leading the vicious cycle of intergenerational malnutrition [10].

Globally, childhood malnutrition is the most pressing public health problem [11], predominantly in developing countries as it has primarily been directly or indirectly responsible for $60.0 \%$ of the 10.9 million annual child deaths [12]. More than two-thirds of these deaths are associated with inappropriate child feeding practices which occur during the first 2 years of life [13]. Furthermore, malnourished children are at higher risks of repeating grades in school and dropping out from schools which is costly to the families and educational systems of countries [14]. In Ethiopia, malnutrition is a significant public health problem among infants and young children. According to the 2011 demographic and health survey (DHS) report of the country, about 44.4, 28.7 and $9.7 \%$ of under 5 years of age Ethiopian children were stunted, underwieght, and wasted, respectively [15].

The quality of a child's food is dependent on meal frequency and food groups contained in the diet. However in most of developing countries, infants and young children are directly introduced to regular household diets made of cereal or starchy foods [16] which are poor in quality. Moreover, the 2014 report of the International Food Policy and Research Institute on global nutrition situation indicated that inorder to attain nutritional requirment and prvent deficiencies, child feeding practie in the first 2 years of age needs special attention in
Africa [13]. In the Sub-Sahara African region, inadequate IYCF practices are among causes of high childhood morbidity and mortality [17].

The Government of Ethiopia has been implementing a number of strategies [the 2004 National Strategy for IYCF, the 2005/2006 National Nutrition Strategy, the 2008 National Nutrition Program) to improve the levels of IYCF practices [18-20]. However, the country is among nations well known for their low levels of meal frequency and poor dietary diversity practices. According to research reports in Ethiopia, the magnitude of minimum meal frequency and minimum dietary diversity practices among children aged 6-23 months ranges from $44.7-82.0 \%$ and from $10.8-39.1 \%$ [15, 21, 22].

The cause of inappropriate IYCF practices is multifactorial and has diverse contributing factors [5]. Previous studies that aimed at revealing the determinants of inappropriate IYCF practices among infants and young children reported that socio-economic and demographic characteristics [age and sex of the child, residence, mothers level of education and occupation, occupational and educational status fathers, household family size, household wealth index]; cultural and traditional beliefs related factors [traditions, cultural beliefs, maternal perception IYCF, taboos on IYCF]; co-morbidity and health care utilization characteristics of children and mothers' [child illness in the past 1 week, child growth monitoring participation, antenatal (ANC) and mothers' counseling on IYCF during PNC service visits] [23-32] were factors influencing IYCF practices. Thus, all these factors impacted minimum meal frequency and dietary diversity practices [33, 34].

It has been well concluded that any interventions that occur after the first 2 years of a child's life have no significant impact on the growth and development of children [35]. Improving the quantity and quality of a child's food in this critical windows period is among the most cost effective strategies to improve overall health and ensure nutritional wellbeing [36]. There are strong evidences that appropriate meal frequency and dietary diversity practices lead to better health and growth outcomes among children [37-40]. The role of evidence 
based health and nutrition information as predictors of minimum meal frequency and dietary diversity practices is significant in improving the levels of inadequate IYCF practices [36], and reducing childhood malnutrition [41]. However, studies are scarce in the predominantly agrarian society of Bale zone, Southeast Ethiopia. With this background in mind, the present study was carried out to identify the determinants of minimum meal frequency and dietary diversity practices among children aged 623 months in the zone. The findings the study meant to provide evidences to programme managers and policymakers to design and implement appropriate interventions to improve the levels of inadequate meal frequency and poor dietary diversity practices and reduce childhood malnutrition, morbidity and mortality in the predominantly agrarian society of Bale zone, Southeast Ethiopia.

\section{Methods}

\section{Study design, time and settings}

Community based cross sectional study was conducted from January-June 2016 at Bale Zone, Southeast Ethiopia. Bale zone is one of the 18 zones found in Oromia regional state with a catchment area of $43,690.56 \mathrm{~km}^{2}$. According to the 2015 population projection, there are a total of $1,807,279$ populations with 376,516 households living in the study area. Bale zone, have a total of 20 woreda and 389 (43 urban and 345 rural) kebeles (the smallest administrative units in Ethiopia) [42]. Furthermore, according to the 2016 Bale Zone Health Department Biannual Health Development report, there are a total of 29, 751 infants and young children aged 6-23 months found in the study area [43].

\section{Source population, sample size calculation and sampling procedure}

The source population was children aged 6-23 months, living in Bale zone, Southeast Ethiopia. Sample size was determined by using a single population proportion formula. The prevalence $(\mathrm{P})$ of minimum meal frequency and minimum dietary diversity practices was taken as $44.7 \%$ and $10.8 \%$, respectively [15], with the assumptions of a $95 \%$ of confidence level and 5\% margin of error (d) for both study factors. Then, the result for minimum meal frequency and minimum dietary diversity scores were 380 and 148, respectively. However, to get a larger value, we took 380 as our required sample size estimation. Finally, a sample size of 836 was obtained after adjusting 2 as a design effect and anticipating 10\% as a non-response rate. A multi-stage sampling technique was used in the study. Initially, out of 20 'woredas', four were selected as representative by the lottery method. Kebeles found in the selected woredas were further stratified into urban and rural. A total of 5279 infants and young children aged 6-23 months living in the selected kebeles were obtained from the kebele health post log books and used to calculate the sampling fraction (k). Furthermore, proportional allocation was considered to estimate the total number of children to participate in each selected kebele. Then, a systematic sampling technique was employed to recruit the study participants. The younger child was purposively selected in the households with more than one eligible study subject. When mother-child pairs were not available at the time of data collection, two repeated visits were made.

\section{Data collection instrument and procedures}

An interviewer administered, pretested, and structured questionnaire was used to collect data. The questionnaire was designed with three major sections in mind. The first part was on socio-demographic and economic related characteristics of the child and family. The second part involved dietary practice, co-morbidity status, and health care utilization related characteristics of the child while the third section focused on household environmental and maternal health care utilization characteristics of the household/family. To maintain consistency, the questionnaire was first translated from English to Afaan-Oromo, the native language of the study area, and then retranslated to English by professional translators. A total of 14 health professionals (two experienced public health experts as supervisors and 12 clinical nurses as data collectors) were recruited for the data collection.

The minimum dietary diversity score (DDS) assessment were done by using a $24-\mathrm{h}$ recall method, and the score is used to reflect the micronutrient adequacy of the diet of the infant and young child [44]. DDS were validated for several age/sex groups as proxy measures for both macro and micronutrient sufficiency of the diet [45-47]. Additionally, DDS was significantly associated with the micronutrient density of complementary foods for infants and young children [48]. The tool uses an open recall method to gather information for all food groups and drinks consumed over a given reference period of $24 \mathrm{~h}$. Mothers of infants and young children were requested to list out food groups and drinks consumed by their children in the previous $24 \mathrm{~h}$ of the survey. The minimum dietary diversity score was computed based on 7 food groups which contains grains, roots and tubers; legumes and nuts; dairy products; flesh foods; eggs; vitamin-A rich fruits and vegetables; other fruits and vegetables. Likewise, the minimum meal frequency practice of infants and young children was estimated by using a 24-h recall technique. Mothers of children were requested to count their children's meal frequency in the past $24 \mathrm{~h}$ of the interview [49].

Wealth index was used to indicate the socio-economic status of study participants' households. It was computed 
by using composite asset indicators for urban and rural residents. A total of 11 composite asset indicators (owning farm land, per-hectare productivity of the farm (in quintals), television set, refrigerator, mobile telephone, availability of electric power, fixed phone, bicycle, cart, number of milk caws and number of oxen) via a principal components analysis (PCA) were used to construct the wealth indexes of households. Finally, the wealth index was classified into five categories (Lowest, Second, Middle, Fourth and Highest) [15].

\section{Inclusion and exclusion criteria}

All infants and young children aged 6-23 months with their mothers and who lives for at least 6 months in the study area were included in the study. However, those infants and young children whose mothers were seriously ill and not able to respond the interviews were excluded from the study.

\section{Operational definitions Minimum meal frequency}

Minimum is defined as proportion of children aged 623 months; who receive solid, semi-solid, or soft foods at the minimum numbers of two and three times for children aged 6-8 months, and 9-23 months respectively [49].

\section{Minimum dietary diversity score}

Is proportion of infants and young children aged 623 months who received foods and drinks from $\geq 4$ food groups in the previous $24 \mathrm{~h}$ [49].

\section{Afaan-Oromo}

Is an Afro-asiatic and Cushitic family's language spoken by about 30 million people in Ethiopia [50].

\section{Woreda}

Is the third level administrative divisions in Ethiopia. It contained an estimated population size of 50,000-150,000 in its catchment [51].

\section{Kebele}

Is the smallest administrative unit in Ethiopia. It contained an estimated population size of $5000-15,000$ in its catchment [51].

\section{Data quality issues}

A training of 3 days was given to recruited data collectors and supervisors. The training mainly focused on equipping the trainees with information about the objective of the study, techniques of interview, collection of data, and relevant ethical issues. The data collection tool was pretested on $5 \%$ of the study subjects out of the selected kebeles. During the pre-test, the acceptability and applicability of the procedures and tools were evaluated. All questioners were regularly checked for completeness, clarity, and consistency by the respective supervisors. The investigators coordinated the overall activities of data collection. Data validity and reliability were maintained through a close supervision of data collectors and supervisors by the investigators.

\section{Data processing and analysis}

Data was entered into EPI INFO version 3.5.3 and analyzed by using Statistical Package for Social Sciences (SPSS) version 20. Descriptive statistics, including frequencies and proportions were used to summarize the study variables. A binary logistic regression model was used to find out factors associated with minimum meal frequency and minimum dietary diversity practices. Those variables in both minimum meal frequency and dietary diversity score a $\mathrm{P}-$ Values of $<0.2$ in the bivariate analysis were transferred to the multivariable analysis to control the possible effect of confounders. The Adjusted Odds Ratio (AOR) with a 95\% of confidence intervals was used to notify the strength of association, and at $\mathrm{P}$ Values of $\leq 0.05$ was used to declare the statistical significance in the multivariable analysis.

\section{Results}

Socio-demographic and economic characteristics related variables of the child and the family

A total of 801 mother-child pairs with a response rate of 95.8\% were included in the final data analysis process. The mean age of mothers/caretakers was 26.5 years with nearly half of them in the age ranges of 25-35 years. About 16.9, 17.4, and $65.8 \%$ of infants and young children were aged $6-8,9-11$, and 12-23 months respectively. More than $70 \%$ of the mothers of the infants and young children attended formal education. About 18.9 and $19.7 \%$ of households were found at the lowest and highest socio-economic levels, respectively (Table 1).

\section{Dietary practice and co-morbidity status related characteristics of children}

More than 91 percents of study subjects were breast feeding during the interview. About $73.5 \%$ of study subjects were participated growth monitoring in the previous 1 month of the survey. As mothers of children confirmed that, more than $20 \%$ of children were experienced complaints of illness in the past 1 week of the survey (Table 2).

Food groups consumed by children aged 6-23 months in the previous $24 \mathrm{~h}$ of the survey

Proportion of infants and young children aged 623 months, who practiced a minimum dietary diversity scores were28.5\% [95\% CI: 0.254, 0.316]. More than 19 
Table 1 Socio-demographic and economic related characteristics of children aged 6-23 months and the family at Bale zone, Southeast Ethiopia, 2016 $(n=801)$

\begin{tabular}{|c|c|c|c|c|c|c|c|}
\hline & \\
\hline Characteristics & Category & Frequency & Percentage & & Middle & 160 & 20.0 \\
\hline \multirow{3}{*}{$\begin{array}{l}\text { Age of the child } \\
\text { (in months) }\end{array}$} & 6-8 month & 135 & 16.9 & & Fourth & 162 & 20.2 \\
\hline & 9-11 months & 139 & 17.4 & & Highest & 158 & 19.7 \\
\hline & $12-23$ months & 527 & 65.8 & \multirow{2}{*}{$\begin{array}{l}\text { Maternal exposure to } \\
\text { different medias }\end{array}$} & Yes & 499 & 62.3 \\
\hline Sex of the child & Male & 468 & 58.4 & & No & 302 & 37.7 \\
\hline
\end{tabular}

$\begin{array}{llll}\text { Birth order of the child } \quad 1 s t & 245 & 30.6\end{array}$

$\begin{array}{lll}\text { 2nd } & 199 & 24.8\end{array}$

3rd $\quad 125 \quad 15.6$

$\geq 4$ th $\quad 232 \quad 29.0$

Maternal age (in years) $\quad<25$ years $\quad 312 \quad 39.0$

25-35 years $\quad 393 \quad 49.0$

$\begin{array}{lll}\geq 36 \text { years } & 96 & 12.0\end{array}$

Religion

Muslim $\quad 503 \quad 62.8$

Orthodox $\quad 258 \quad 32.2$

$\begin{array}{lll}\text { Protestant } & 34 & 4.2\end{array}$

$\begin{array}{lll}\text { Catholic } & 6 & 0.7\end{array}$

Maternal marital status $\quad$ Married $\quad 752 \quad 93.9$

Single $\quad 23 \quad 2.9$

Divorced $\quad 26 \quad 3.2$

Mothers educational level

|lliterate $\quad 195$

Informal 31

education

Formal education 575

Employment status of the mother

Educational status of the
father
Employment status of the
father

House wife $\quad 612$

Farmer $\quad 49$

Governmental 50 employed

Daily labourer $\quad 10 \quad 1.2$

$\begin{array}{lll}\text { Merchant } \quad 80 & 10.0\end{array}$

Illiterate $\quad 119 \quad 15.8$

Informal $\quad 44 \quad 5.9$

education

Formal education 589

Farmer $\quad 416$

Merchant

166

Governmental employed

Daily labourer $\quad 45$

Household family size

$\leq 3$

246

$4-6$

$\geq 7$

139

Household wealth index
Table 1 Socio-demographic and economic related characteristics of children aged 6-23 months and the family at Bale zone, Southeast Ethiopia, 2016 $(n=801)$ (Continued)

$\%$ of infants and young children was received foods prepared from grains, roots and tubers. Only $8.9 \%$ of children were consumed flesh foods in the previous $24 \mathrm{~h}$ of the interview (Fig. 1).

\section{Household environmental and maternal health care utilization characteristics}

More than $75 \%$ of children mothers had $\geq 4$ times of antenatal care (ANC) service visit to the nearest health institution during their child pregnancy life. While, about $68.5 \%$ of mothers had $\geq 3$ times postnatal care (PNC) service visits during the interview. Beside to this, near to $60 \%$ of mothers was received nutrition counselling on IYCF practices by health professionals during their visit. Latrine was available in more than $95 \%$ of study participants household (Table 3).

\section{Factors associated with minimal meal frequency}

The bivariate logistic regression analysis showed that child age, household family size, parity of mother, maternal counselling status on IYCF during ANC and PNC service visits were associated with minimal meal

Table 2 Dietary practice and co-morbidity status related characteristics of children aged 6-23 months at Bale zone, Southeast Ethiopia, $2016(n=801)$

\begin{tabular}{llll}
\hline Characteristics & Category & Frequency & Percentage \\
\hline Currently breast feeding & Yes & 734 & 91.6 \\
& No & 67 & 8.4 \\
Growth monitoring in the in past & Yes & 589 & 73.5 \\
one month & No & 212 & 26.5 \\
Child history of illness in the past & Yes & 179 & 22.3 \\
1 week & No & 622 & 77.7 \\
Timely initiation of complementary & Yes & 498 & 62.2 \\
foods & No & 303 & 37.8 \\
Minimum meal frequency & Yes & 548 & 68.4 \\
& No & 253 & 31.6 \\
Minimal dietary diversity scores & Yes & 228 & 28.5 \\
& No & 573 & 71.5 \\
Minimal acceptable diet & Yes & 207 & 26.8 \\
& No & 594 & 73.2 \\
\hline
\end{tabular}

Second 


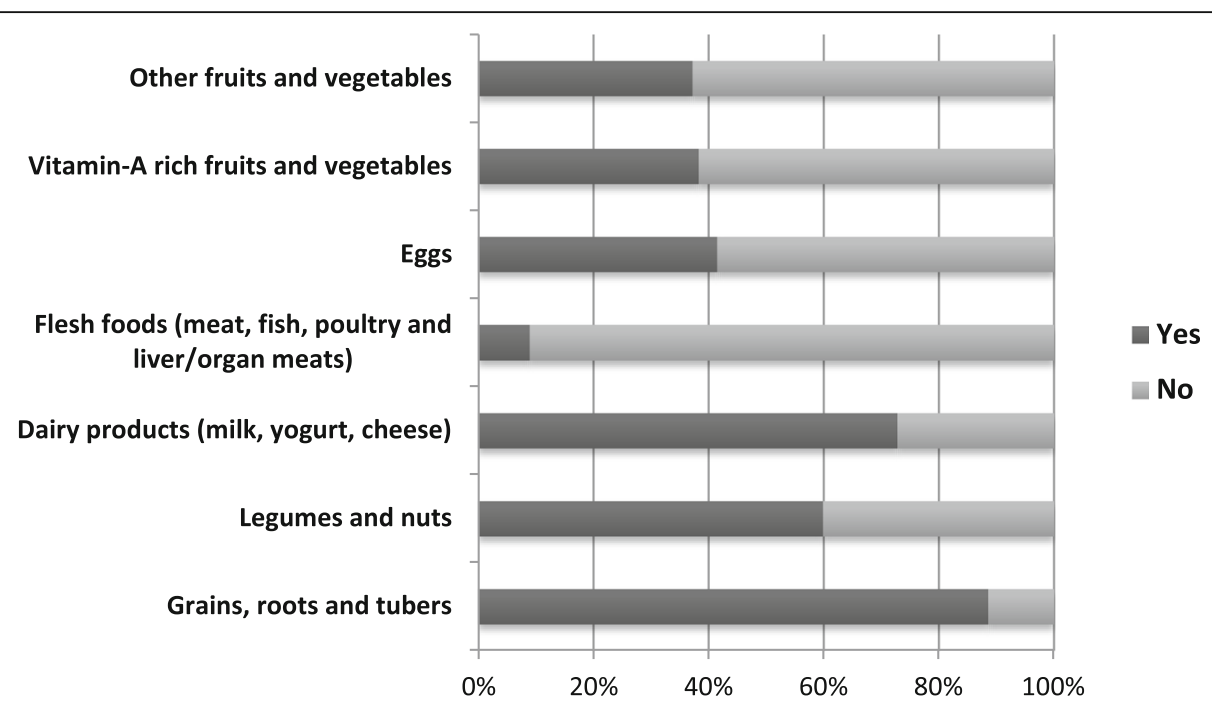

Fig. 1 Types of food groups consumed by children aged 6-23 months in the previous $24 \mathrm{~h}$ of the survey at Bale zone, southeast Ethiopia, 2016

Table 3 Household environmental and maternal health care utilization characteristics of children aged 6-23 months at Southeast Ethiopia, $2016(n=801)$

\begin{tabular}{|c|c|c|c|}
\hline Characteristics & Category & Frequency & Percentage \\
\hline \multirow[t]{3}{*}{ Parity of the mother } & $1-2$ & 432 & 52.8 \\
\hline & $3-6$ & 321 & 40.1 \\
\hline & $\geq 5$ & 57 & 7.1 \\
\hline \multirow[t]{2}{*}{ History of antenatal care visit } & Yes & 742 & 92.6 \\
\hline & No & 59 & 7.4 \\
\hline \multirow[t]{2}{*}{ Frequency of antenatal care visit } & $1-3$ & 169 & 22.8 \\
\hline & $\geq 4$ & 1573 & 77.2 \\
\hline \multirow{2}{*}{$\begin{array}{l}\text { Counselling on infant and young } \\
\text { child feeding during antenatal } \\
\text { care visit visit }\end{array}$} & Yes & 445 & 60.0 \\
\hline & No & 297 & 40.0 \\
\hline \multirow[t]{2}{*}{ Postnatal care service visit } & Yes & 676 & 84.4 \\
\hline & No & 125 & 15.6 \\
\hline \multirow{3}{*}{$\begin{array}{l}\text { Frequency of postnatal care } \\
\text { service visit }\end{array}$} & 1 Times & 42 & 6.2 \\
\hline & 2 Times & 171 & 25.3 \\
\hline & $\geq 3$ times & 463 & 68.5 \\
\hline \multirow{2}{*}{$\begin{array}{l}\text { Counselling on infant and young } \\
\text { child feeding during postnatal } \\
\text { visit }\end{array}$} & Yes & 402 & 50.2 \\
\hline & No & 274 & 34.2 \\
\hline \multirow{2}{*}{$\begin{array}{l}\text { Household source of drinking } \\
\text { water }\end{array}$} & Protected & 691 & 86.3 \\
\hline & Unprotected & 110 & 13.7 \\
\hline \multirow[t]{2}{*}{ Availability of home garden } & Yes & 256 & 32.0 \\
\hline & No & 545 & 68.0 \\
\hline \multirow[t]{2}{*}{ Availability of latrine } & Yes & 763 & 95.3 \\
\hline & No & 38 & 4.7 \\
\hline
\end{tabular}

frequency. However, in the multivariate regression analysis only the age of the child and parity of the mother remained to affect minimum meal frequency practice among children aged 6-23 months. As a result, the odds of minimum meal frequency were $71 \%$ times less likely among children aged 6-8 months than those aged 1223 months $(\mathrm{AOR}=0.29,95 \% \mathrm{CI}: 0.28-0.94)$. Parity of the mother was another factor significantly associated with minimum meal frequency. As a result, para-one and two mothers were 2.8 times more likely to practice minimum meal frequency to the child than para-five and above mothers $(\mathrm{AOR}=2.8,95 \% \mathrm{CI}: 1.11-7.50)$ (Table 4).

\section{Factors associated with minimal dietary diversity scores (DDSs)}

Maternal educational status, household family size, level of exposure to different media, parity of mother, child illness in the past 1 week of the survey, mothers counselling status on IYCF during ANC, and PNC service visits were identified as factors associated with minimum dietary diversity score in the bivariate regression analysis. However, in the multivariate analysis, mothers' educational status, child illness in the past 1 week of the survey, and maternal counselling status on IYCF during PNC service visits were factors statistically associated with minimal dietary diversity practice in the study area. Accordingly, minimum dietary diversity practice of study subjects was $48 \%$ times less likely among illiterate mothers than mothers with formal education $[\mathrm{AOR}=0.52,95 \%$ CI: 0.28-0.94]. A child's history of illness in the week preceding the interview decreased the practice of minimum dietary diversity scores by $56 \%$ times [AOR $=0.44,95 \%$ CI: 0.26-0.73] Likewise, the odds of minimum dietary diversity practice of the child were 2.6 times higher among mothers 
Table 4 Bivariate and multivariate analysis of factors associated with minimal meal frequency among children aged 06-23 months at Bale zone, Southeast Ethiopia, 2016

\begin{tabular}{|c|c|c|c|c|c|}
\hline \multirow[t]{2}{*}{ Characteristics } & \multicolumn{3}{|c|}{ Minimal meal frequency } & \multirow[b]{2}{*}{ COR $(95 \% \mathrm{Cl})$} & \multirow[b]{2}{*}{ AOR $(95 \% \mathrm{Cl})$} \\
\hline & Category & Yes & No & & \\
\hline \multirow[t]{3}{*}{ Household family size } & $\leq 3$ & 169 & 77 & $1.6(1.05,2.49)$ & $0.9(0.42,1.95)$ \\
\hline & $4-6$ & 299 & 117 & $1.9(1.26,2.80)$ & $1.48(0.81,2.7)$ \\
\hline & $\geq 7$ & 80 & 59 & 1.00 & 1.00 \\
\hline \multirow[t]{3}{*}{ Parity of the mother } & $1-2$ & 308 & 115 & $2.5(1.47,4.53)$ & $2.8(1.11,7.50)^{*}$ \\
\hline & $3-4$ & 211 & 110 & $1.8(1.04,3.26)$ & $1.5(0.69,3.66)$ \\
\hline & $\geq 5$ & 29 & 28 & 1.00 & 1.00 \\
\hline \multirow[t]{3}{*}{ Age of the child } & $6-8$ & 67 & 68 & $0.26(0.18,0.40)$ & $0.29(0.28,0.94)^{*}$ \\
\hline & $9-11$ & 67 & 72 & $0.25(0.17,0.37)$ & $0.24(0.15,0.39)^{*}$ \\
\hline & $12-23$ & 414 & 113 & 1.00 & 1.00 \\
\hline \multirow[t]{2}{*}{ Counselling on IYCF during ANC visit } & Yes & 328 & 117 & $1.83(1.33,2.49)$ & $1.28(0.79,2.05)$ \\
\hline & No & 180 & 117 & 1.00 & 1.00 \\
\hline \multirow[t]{2}{*}{ Counselling on IYCF during PNC visit } & Yes & 302 & 100 & $1.93(1.38,2.69)$ & $1.25(0.78,1.99)$ \\
\hline & No & 167 & 107 & 1.00 & 1.00 \\
\hline
\end{tabular}

Note: *Significant at P-Value <0.05; DDSs-Dietary Diversity Scores; COR-Crude Odds Ratio; AOR-Adjusted Odds Ratio

counselled on IYCF practice during PNC visits $[\mathrm{AOR}=2.6$, 95\% CI: 1.59-4.51] (Table 5).

\section{Discussion}

The proportion of children aged 6-23 months who received the recommended minimal meal frequency and minimum diversified food groups was $68.4 \%$ [95\% CI: $0.652,0.716$ ] and $28.5 \%$ [95\% CI: $0.254,0.316]$, respectively. In the present study, the minimum meal frequency was higher than reports from Ethiopia [44.7 and 50.4\%] [15, 21], Ghana [57.3\%] [52], Democratic Republic of Congo (30\%] [53], and India [42\%] [31]. The possible

Table 5 Bivariate and multivariate regression analysis of factors significant with minimal DDSs among children aged 06-23 months at Bale zone, Southeast Ethiopia, 2016

\begin{tabular}{|c|c|c|c|c|c|}
\hline \multirow[t]{2}{*}{ Characteristics } & \multicolumn{3}{|c|}{ Minimal dietary diversity practice } & \multirow[b]{2}{*}{ COR $(95 \% \mathrm{Cl})$} & \multirow[b]{2}{*}{ AOR(95\% Cl) } \\
\hline & Category & Yes & No & & \\
\hline \multirow[t]{3}{*}{ Educational status of the mother } & Illiterate & 36 & 159 & $0.46(0.32,0.69)$ & $0.52(0.28,0.94)^{*}$ \\
\hline & Informal education & 4 & 27 & $0.30(0.10,0.88)$ & $0.20(0.04,0.91)^{*}$ \\
\hline & Formal education & 188 & 387 & 1.00 & 1.00 \\
\hline \multirow[t]{3}{*}{ Household family size } & $<4$ & 80 & 166 & $1.9(1.16-3.12)$ & $2(0.89-4.5)$ \\
\hline & $4-6$ & 120 & 296 & $1.6(1.0,2.56)$ & $1.2(0.60,2.37)$ \\
\hline & $>6$ & 28 & 11 & 1.00 & 1.00 \\
\hline \multirow[t]{2}{*}{ Exposure to different media } & Yes & 167 & 322 & $1.96(1.41,2.78)$ & $1.27(0.82,1.95)$ \\
\hline & No & 61 & 241 & 1.00 & 1.00 \\
\hline \multirow[t]{3}{*}{ Parity of the mother } & $1-2$ & 129 & 294 & $3.13(1.38,7.0)$ & $1.6(0.48,5.53)$ \\
\hline & $3-6$ & 92 & 229 & $2.8(1.25,6.56)$ & $2.5(0.84,7.88)$ \\
\hline & $\geq 7$ & 7 & 50 & 1.00 & 1.00 \\
\hline \multirow[t]{2}{*}{ Child illness in the past 1 week } & Yes & 34 & 145 & $0.51(0.34,0.78)$ & $0.44(0.26,0.73)^{*}$ \\
\hline & No & 194 & 428 & 1.00 & 1.00 \\
\hline \multirow{2}{*}{$\begin{array}{l}\text { Counselling on infant and } \\
\text { young child feeding during } \\
\text { antenatal care visit }\end{array}$} & YES & 162 & 283 & $2.4(1.7,3.4)$ & $1.57(0.92,2.6)$ \\
\hline & No & 57 & 240 & 1.00 & 1.00 \\
\hline \multirow{2}{*}{$\begin{array}{l}\text { Counselling on infant and } \\
\text { young child feeding during } \\
\text { postnatal care visit }\end{array}$} & Yes & 149 & 253 & $4.1(2.7,6.2)$ & $2.6(1.59,4.45)^{*}$ \\
\hline & No & 34 & 240 & 1.00 & 1.00 \\
\hline
\end{tabular}


reasons for the dissimilarity between studies could be the difference in religious and socio-cultural beliefs, all of which can influence appropriate infant and young child feeding practices [16]. The role of regional differences among studies highlights the importance of ensuring interventions to improve proper child feeding practices in the local contexts [13]. Another possible explanation may be the time gap among studies, i.e. the previous local study [15] was carried out over 5 years ago. However, our finding on minimum meal frequency was lower than the [82.0\%] of reported in Ethiopia [22] and [71.1\%] [30], [81\%] [54], and [84\%] [55] in such Asiatic and Latin American nations, like Sri Lanka, Bangladesh, and Nepal, respectively. The possible reason for the variability among reports could be the difference in socio-economic status of the household, which can further show the purchasing power of families to feed their children. In this study, more than $60 \%$ of children's households were found in the middle and low level of wealth status. The important role of household resource is that it helps in determining the quality and quantity of complementary feeding for the child [33]. Furthermore, it may be due to variations in the degree of health seeking behavior and knowledge on IYCF practices among study communities. The present finding for minimum dietary diversity practice was somewhat better compared to previously documented results in Ethiopia [10.812.6\%] [15, 21], Burkina Faso [14\%] [56], Mali [16\%] [48], and India [15.2\%] [31]. On the other hand, this finding on minimum dietary diversity practice was lower than that of studies done in Ethiopia [39.1\%] [22], and other developing nations, like Nepal [34\%] [57], India [33\%] [58], Bangladesh [41.9\%] [54], and Sri Lanka [71\%] [30]. The possible reason for the differences among studies might be due to variations in study settings, sample size consideration, and time gap among studies. Our study was conducted on a small sample size. But, in previous local study [15], more heterogeneous and larger study community was participated in different settings with varying socio-cultural beliefs on infant and young child feeding practices.

Child age was significantly associated with minimum meal frequency. The odds of minimum meal frequency were lesser among children aged 6-11 months than children aged 12-23 months. This indicates that minimum meal frequency is positively associated with the age of infants and young children, implying that the practice of minimum meal frequency increases as the age of children increases. The result was in line with those of studies conducted in Ethiopia [21], Ghana [52], and other Asian countries, like India [58] and Sir Lanka [30], i.e., children aged 6-11 months independently had higher risks for decreased minimal meal frequency practice than their counter parts. This was further evidenced by the fact that, age is an important consideration in assessing meal frequency and dietary adequacy of infant and young child feeding practices [21]. This is again testified by the fact that as the child grows older the frequency of meal increases and diets become more diverse. Additionally, it is because eruption of the teeth influences when the child is introduced to complementary foods, but the process typically leads to loss of appetite and negatively affecting the frequencies of meals for the child $[29,59]$. Besides, it may be due to the maternal perception of the younger child and the low ability of the child's intestine to digest and absorb foods. Moreover, mothers may perceive that introducing children to bulks of food would lead to developing many types of infections [60]. Furthermore, these findings show the importance of considering the two events, i.e., practicing age appropriate meal frequency and risks of childhood malnutrition. In most developing countries, infant and young child malnutrition due to inappropriate feeding occurs in the first 2 year of the child's life [13]. The lives of many infants and young children can be saved through a range of cost-effective actions and increasing the rates of age appropriate meal frequency and other IYCF practice indicators at large. Interventions targeted at identifying practices, beliefs, concerns, and constraints relating to minimum meal frequency and addressing them through appropriate messages and counseling have a key role in the health and nutritional status of infants and young children [61].

The number of child births of the mother was another possible factor for attaining minimal meal frequency. The odds of minimal meal frequency increase nearly three times among children of para $\leq$ two mother. The possible reason may be that a mother with fewer childbirths may have a better commitment and good motivation to feed and care her child appropriately. Additionally, having fewer childbirths may increase mothers' level of love for children which may inversely influence the level and type of child care and feeding practices. Another possible explanation could be that mothers with few childbirths may have better level of education than multi-para mothers. This is due to the fact that mothers' level of education can strongly influence on the decision of having number of childbirths in their reproductive age [62]. As well, educated mothers are more inclined to practice scientifically proven feeding recommendations for their children [63].

Unlike other studies $[22,53,54,58]$, no factor was identified to have a significant association with both minimum meal frequency and dietary diversity practices in this study. After we controlled the possible effects of other factors in the multivariate regression analysis mothers' education, child illness in the past 1 week of the survey and maternal counseling on IYCF practices during PNC service visits remained determinant factors 
for minimum dietary diversity practice in this study community.

Maternal educational status was significantly associated with minimum dietary diversity practice of infants and young children. Mothers with better educational status were more likely to practice minimum dietary diversity for their children. The importance of mothers' education for child health, degree of nutrition and feeding practice has been well investigated in Ethiopia [64], Nepal [55], Bangladesh [54] and India [58]. This is highly supported by the fact that, mother's education has a strong role in increasing thier level of confidence, command over resources independently, and adherence to recommended IYCF practices [64,65]. Education is a proxy measure for socioeconomic wellbeing and researchers argue that mothers' with better education tend to have more work opportunities and better wealth than mothers' with lower educational status $[60,66]$. This could increase their purchasing power of different food groups and feeding diversified foods for their children.

Child illness in the week preceding the survey influenced minimum dietary diversity practice of infants and young children. The present finding was comparable with those of studies done in Ghana [52] and India [67], indicating that child illness in the week absolutely affected the dietary diversity practice of children. This could be due to the fact that common childhood illnesses are known to affect the type of food and feeding practice by reducing the child's appetite [59]. In addition, due to the illness of the child, mothers would reduce giving large amount and different types of food groups to the children.

Maternal PNC service attendance at health institutions was the other possible risk factor for minimum dietary diversity practice in the study area. The risk of not practicing minimum dietary diversity for the child was higher among mothers who had no PNC service visits. The result was in congruence with those of studies in Ethiopia [21] and other developing nations, like Sri Lanka [30], India [67] and Tanzania [68]. These studies showed that mothers' lack of heath institution visits during PNC periods positively determine the dietary diversity practice of infants and young children. This might be due to the fact that mothers' health institution visits during the PNC period has potential opportunities for their getting health and nutrition knowledge by trained health workers on IYCF practices [69]. Health workers have a crucial role in supporting mothers by providing nutrition counseling about balanced diets and appropriate IYCF practices [70]. Thus, they help in ensuring good nutrition in the first couple years of the child's life [34]. Furthermore, this counseling may polish mothers' cultural and traditional beliefs and bring positive influences on IYCF practices [71]. Mothers counselled on IYCF during
PNC visits may become more informed about the importance of providing diversified food groups to their children. Thus, intensified efforts are needed to improve the level of PNC service utilization and to provide nutrition counseling to mothers on IYCF practices.

To sum up, some limitations of the study have to be noted. First, as the design of the study was crosssectional, it was difficult to examine potential temporal relationships. Second, co-morbidity status of the child was conveyed only in the information given by mothers'. This might be subjected to bias as it depends on the mothers' level of knowledge about the illness status of the child. Third, the measurement of child feeding practice again relied on memory, so there may be a possibility of recall bias. Its being unrepresentative of the whole nation is another possible limitation of the study. Nevertheless, the study has successfully showed important trends that can be used in the formulation of other studies and interventions to improve the IYCF practice in the study area.

\section{Conclusion}

This study was found low minimal meal frequency and dietary diversity practice in the predominantly agrarian society of Bale zone, Southeast Ethiopia. No factors were identified to have statistical association with both minimal meal frequency and dietary diversity practice. Child age and parity of mother was the only study variable to have significant association with minimal meal frequency. However, educational status of mothers, child illness in the preceding week of the interview and maternal counselling on IYCF during PNC service visits were independently influenced minimum dietary diversity practice. Improving the level of maternal and child health care utilization, increasing mothers' level of education, and providing health, and nutrition counseling on IYCF during maternal PNC service visits are vital interventions to improve IYCF practices in the study area.

\section{Abbreviations \\ ANC: Ante Natal Care; AOR: Adjusted Odds Ratio; Cl: Confidence Interval; COR: Crude Odds Ratio; DDS: Dietary Diversity Score; IYCF: Infant and Young Child Feeding; PNC: Post Natal Care; SPSS: Statistical Package for Social Science; WHO: World Health Organization}

\section{Acknowledgments \\ We the authors would like to express our sincere gratitude to study subjects for their willingness to participate in this study. The authors' heartfelt thanks will also go to Madda Walabu University for securing ethical issues of the study.}

\section{Funding}

No funding was obtained for this study.

Availability of data and materials

All the required data were presented on the main body of the paper. 


\section{Authors' contributions}

Designed the experiment; MT, HW, SS, TB and MT. Analyzed the data; MT: HW. Wrote the paper; MT, HW. Approved the proposal with some revisions: MT; HW; SS; TB; MT. Prepared and approved the manuscript; MT; HW. All authors read and approved the final manuscript.

\section{Ethics approval and consent to participate}

The study protocol was approved by the Institutional Review Board (IRB) of Madda Walabu University. The ethical clearance was submitted to Bale Zonal Health Bureau, research and technology transfer department. Permission letter (from Bale Zonal Health Bureau, research and technology transfer department) was sent to selected (Agarfa, Jarra, Dinsho and Goba) district health offices. Then, the written permission from each district health offices was submitted to each kebeles administration units in which the actual data collection was undertaken. After the objective of the study was explained, informed verbal consent from every mothers/care taker of study subjects was obtained. The right of study participant to withdraw from the study at any time, without any precondition was disclosed unequivocally. Moreover, confidentiality of the information obtained from every study subjects was guaranteed by all data collectors and investigators using code numbers rather than personal identifiers and keeping the questionnaire locked.

\section{Consent for publication}

Not applicable.

\section{Competing interests}

The authors declare that they have no competing interests.

\section{Publisher's Note}

Springer Nature remains neutral with regard to jurisdictional claims in published maps and institutional affiliations.

\section{Author details}

'Department of Nursing, Madda Walabu University, Bale Goba, Ethiopia. ${ }^{2}$ Department of Public Health, Madda Walabu University, Bale Goba, Ethiopia. ${ }^{3}$ Department of Human Nutrition, Institute of Public Health, College of Medicine and Health Sciences, University of Gondar, Gondar, Ethiopia.

Received: 25 January 2017 Accepted: 5 July 2017

\section{Published online: 13 November 2017}

\section{References}

1. World Health Organization. Guiding principles for feeding non-breastfed children 6-24 months of age. 2005.

2. UNICEF. Infant and young child feeding, nutrition section program. New York: UNICEF; 2012.

3. Medical News Today. Medi lexicon, Intl. What is malnutrition? What causes malnutrition? S.L. : medical news today. MediLexicon, Int, September 26,2014.

4. Saha KK, Frongillo EA, Alam DS, Ariffen SE, Persson LA, Rasmussen KM. Appropriate infant feeding practices result in better growth of infant and young children in rural Bangladish. Bangladesh : Amj clin Nutr. 2008;87: 1852-9

5. World Health Organization. Complementary feeding of young children in developing countries: a review of current scientific knowledge. Geneva: World Health Organization; 1998. p. 237.

6. Hop LT, Gross R, Giay T, Sastroamidjojo S, Schultink W, Lang NT. Premature complementary feeding is associated with poorer growth of Vietnamese children. Vietnam: J Nutr. 2000;130:2683-90.

7. Blössner M, de Onis M. Malnutrition:quantifying the impact at national and local leveles. Geneva: World health Organization; 2005. p. 12.

8. MALUCCIO JA, ADATO M, FLORES R, ROOPNARAINE T. Breaking the cycle of poverty: Nicaraguan red de Protección social. Washington, D.C.: International Food Policy Research Institute; 2005.

9. BEHRMAN J, ALDERMAN H, HODDINOTT J. Hunger and malnutrition. In: Bjorn L, editor. Global crises, global solutions. Cambridge (UK): Cambridge University Press; 2004.

10. Glewwe P, Miguel E. Impact of child health on education in developing countries. North-Holland: Handbook of Development Economics 4; 2007.
11. Black RE, Allen LH, Bhutta ZA, Caulfield LE, de Onis M, Ezzati M, et al. Maternal and child under nutrition: global and regional exposures and health consequences. Lancet. 2008;371(9608):243-60.

12. Black RE, Victora CG, Walker SP, et al. 12.Maternal and child under nutrition and overweight in low-income and middle-income countries. S.L. Lancet. 2013;382:427-51.

13. International Food Policy Research Institute. Global nutrition report. Washington, DC: Actions and Accountability to Accelerate the World's Progress on Nutrition; 2014.

14. African Union Commission. The cost of hunger in Africa: social and economic impact of child under nutrition in Egypt, Ethiopia, Swaziland and Ugand. Addis Ababa: UNECA; 2014.

15. CSA I. Ethiopia demographic and health survey 2011. Central Statistical Agency and ICF International: Addis Ababa; 2012.

16. United Nations Children's Fund. Improving child nutrition: the achievable imperative for global progress. New York: 4; 2013.

17. Lartey A. Maternal and child nutrition in sub-Saharan Africa. Challenges and interventions: Proc Nutr Soc. 2008:105-8.

18. Federal Ministry of Health. Family health department: National Strategy for infant and young child feeding. Addis Ababa: Ethiopia; 2004.

19. Federal Ministry of Health: National Nutrition Strategy. Addis Ababa; Ethiopia: 2005-2006. https://extranet.who.int/nutrition/gina/sites/default/ files/ETH\%202005\%20National\%20Strategy\%20for\%20Child\%20Survival.pd.

20. Federal Ministry of Health. National Nutrition Program. Addis Ababa: Federal Ministry of Health; 2008.

21. Beyene $\mathrm{M}$, et al. Dietary diversity, meal frequency and associated factors among infant and young children in Northwest Ethiopia: a cross- sectional study. BMC Public Health. 2015;15:1007.

22. Yonas F, et al. Infant and young child feeding practice status and associated factors among mothers of under 24-month-old children in Shashemene Woreda, Oromia region, Ethiopia. Open Access Library Journal. 2015;2:e1635.

23. Vishnu $K$, et al. Determinants of complementary feeding practices among Nepalese children aged 6-23 months: findings form demographic and health survey 2011. BMC Pediatr. 2013;13:131

24. World Health Organization and United Nations Children's Fund. Antenatal care in developing countries: promises, achievements and missed opportunities - an analysis of trends, levels and differentials, 1990-2001. Geneva: WHO; 2003.

25. Nira J, et al. Determinants of inappropriate complementary feeding practices in infants and young children: secondary data analysis of demographic and health survey 2006-2007 in Nepal. Matern Child Nutr. 2012;8(Suppl 1):45-59.

26. Gessese D, et al. The practice of complementary feeding and associated factors among mothers of children 6-23 months of age in Enemay district, Northwest Ethiopia. Nutr Food Sci. 2014;44(Iss:3):230-40.

27. Madise NJ, Mpoma M. Child malnutrition and feeding practices in Malawi. Food Nutr Bull. 1997;18:190-201.

28. Kimani-Murage EW, Madise NJ, Fotso JC, et al. Patterns and determinants of breastfeeding and complementary feeding practices in urban informal settlements, Nairobi Kenya. BMC Public Health. 2011;11:396.

29. Khanal V, Sauer K, Zhao Y. Determinants of complementary feeding practices among Nepalese children aged 6-23 months: findings from demographic and health survey 2011. BMC Pediatr. 2013;13:131.

30. Senarath U, Godakandage SSP, Jayawickrama H. et al, Determinants of inappropriate complementary feeding practices in young children in Sri Lanka: secondary data analysis of demographic and health survey 20062007. Maternal \& child nutrition. 2012(8):60-77.

31. Patel A, Pusdekar Y, Badhoniya N, et al. Determinants of inappropriate complementary feeding practices in young children in India: secondary analysis of National Family Health Survey 2005-2006. Maternal \& child nutrition. 2012;8:28-44.

32. Kabir I, Khanam M, Agho KE, et al. Determinants of inappropriate complementary feeding practices in infant and young children in Bangladesh: secondary data analysis of demographic health survey 2007. Maternal \& child nutrition. 2012;8(Suppl 1):11-27.

33. Edem MAT, et al. Feeding practices and malnutrition at the Princess Marie Louise Children's hospital, Accra: what has changed after 80 years? BMC Nutrition. 2016;2:42.

34. Sunguya BF, et al. Effectiveness of nutrition training of health workers toward improving caregivers' feeding practices for children aged six months to two years: a systematic review. Nutr J. 2013;12:66. 
35. Bangladesh demographic and health survey 2007. National Institute of population research and training. Dhaka: Bangladesh demographic and health survey; 2009. p. 381

36. Krebs NF, Michael Hambidge K. Complementary feeding: clinically relevant factors affecting timing and composition. Am J Clin Nutr. 2007;85(suppl): 639-4.

37. Arimond M, Daelmans B, Dewey KG. Indicators for feeding practices in children. Lancet. 2008;371:541-2.

38. Chelimo F. L. (2008). Assessment of complementary feeding practices and nutritional status among children in Athi-River, Machakos district Kenya.

39. Ceatan MC, Dasilva SG, Souza FI, Sarni RO. Complementary feeding: inappropriate practices in infants. Journal of Pediatrics (Rio Jenerio). 2010;86: 196-201.

40. Nyangweso PM, Odhiambo MO, Ondunga P, Korir MK, Kipsat MJ, Seren AK Household food security in Kitui District. Determinants of Dietary Diversity; Africa Crop Science Conference Proceeding Egypt. 2007:8:1383-9.

41. World Health Organization. Global strategy for infant and young feeding. Geneva: WHO. 2003.

42. Bale Zone Agricultural and Rural Development Office. Annual report on agriculture and rural development Army, annual report. 2015.

43. Bale Zone Health Department. Biannual report on health development Army, biannual report. 2016.

44. Steyn NP, Nel JH, Nantel G, Kennedy G, Labadarios D. Food variety and dietary diversity scores in children: are they good indicators of dietary adequacy? Public Health Nutr. 2006;9(5):644-50.

45. Foote J, Murphy S, Wilkens L, Basiotis P, Carlson A. Dietary variety increases the probability of nutrient adequacy among adults. J Nutr. 2004;134: 1779-85.

46. Mirmiran P, Azadbakht L, Esmaillzadeh A, Azizi F. Dietary diversity scores in adolescents- a good indicator of the nutritional adequacy of diets. Asia Pac J Clin Nutr. 2004;13(1):56-60.

47. Savy M, Martin-Prevel Y, Sawadogo P, Kameli Y, Delpeuch F. Use of variety/ diversity scores for diet quality measurement: relation with nutritional status of women in a rural area in Burkina Faso. Eur J Clin Nutr. 2005:59:703-16.

48. Hatloy A, Torheim L, Oshaug A. Food variety-a good indicator of nutritional adequacy of the diet? A case study from an urban area in Mali, West Africa. Eur J Clin Nutr. 1998;52(12):891-8.

49. World Health Organization. Indicators for assessing infant and young child feeding practices. Geneva: WHO Press; 2010.

50. Ethnologue, Languages of Ethiopia. Retrieved August 2013.

51. Yilmaz C, et al. Local government discretion and accountability in Ethiopia: international studies program, Andrew young School of Policy Studies, Georgia State University; 2008. p. 2-5. Retrieved 2013

52. Saaka et al. Magnitude and factors associated with appropriate complementary feeding among children 6-23 months in Northern Ghana BMC Nutrition. 2016;2:2.

53. World Health Organization: Indicators for assessing infant and young child feeding practices part 3: country profiles. 2010

54. Kabir I, Khanam M, Agho KE, Mihrshahi S, Dibley MJ, Roy SK. Determinants of inappropriate complementary feeding practices in infant and young children in Bangladesh: secondary data analysis of demographic health survey 2007. Matern Child Nutr. 2012;8(s1):11-27.

55. Gautam KP, et al. Determinants of infant and young child feeding practices in Rupandehi, Nepal. BMC Res Notes. 2016;9:135.

56. Sawadogo PS, Martin-Prevel Y, Savy M, Kameli Y, Traissac P, Traore AS, et al. An infant and child feeding index is associated with the nutritional status of 6- to 23-month-old children in rural Burkina Faso. J Nutr. 2006;136:656-63.

57. Joshi N, Agho KE, Dibley MJ, Senarath U, Tiwari K. Determinants of inappropriate complementary feeding practices in young children in Nepal: secondary data analysis of demographic and health survey 2006. Matern Child Nutr. 2011:8(Suppl 1):45-59.

58. Khan AM, Kayina P, Agrawal P, Gupta A, Kannan AT. A study on infant and young child feeding practices among mothers attending an urban health center in East Delhi. Indian J Public Health. 2012;56(4):301.

59. Melkam A, Mesele M, Birhanu Z, et al. Dietary diversity and meal frequency practices among infant and young children aged 6-23 months in Ethiopia: a secondary analysis of Ethiopian demographic and health survey 2011. J Nutr Metabol. 2013;2013:782931.

60. Ng C, Dibley M, Agho K. Complementary feeding indicators and determinants of poor feeding practices in Indonesia: a secondary analysis of 2007 demographic and health survey data. Public Health Nutr. 2011;5(5):827-39.
61. Bhutta ZA, Das JK, Rizvi A, Gaffey MF, Walker N, Horton S, Webb P, Lartey A, Black RE, Group TLNIR. Evidence-based interventions for improvement of maternal and child nutrition: what can be done and at what cost? Lancet. 2013:382(9890):452-77.

62. Rutstein SO, Rojas G. Guide to DHS statistics, demographic and health surveys. Calverton: ORC Macro; 2006.

63. Ministry of Health and Population (MOHP), New ERA, and ICF International, Nepal Demographic and Health Survey. Ministry of Health and population. Kathmandu: New ERA, and ICF International, Calverton, Md, USA, 2012; 2011.

64. Mekbib E, et al. Magnitude and factors associated with appropriate complementary feeding among mothers having children 6-23 months-ofage in northern Ethiopia; a community-based cross-sectional study. Journal of Food and Nutrition Sciences. 2014;2(2):36-42.

65. Mamiro PS, Kolsteren P, Roberfroid D, Tatala S, Opsomer AS, van Camp JH. Feeding practices and factors contributing to wasting, stunting, and irondeficiency anemia among 3-23-month old children in Kilosa district, rural Tanzania. J Health Popul Nutr. 2005;23(3):222-30.

66. Vaughan L, Weber C, Kemberling S. Longitudinal changes in the mineral content of human milk. Am J Clin Nutr. 1979:32:23016.

67. Aggrawal A, Verma S, Feridi MA, Chand D. Complementary feeding-reasons for inappropriateness in timing, quality and consistency. Indian J Pediatr. 2008;75:49-56.

68. Rose V, Baines SK, Agho KE, Dibley MJ. Factors associated with inappropriate complementary feeding practices among children aged 6-23 months in Tanzania. Matern Child Nutr. 2012;10(4):545-61.

69. Bhandari N, Mazumder S, Bahl R, Martines J, Black RE, Bhan MK, Group IFS. Use of multiple opportunities for improving feeding practices in under-twos within child health programmes. Health Policy Plan. 2005;20(5):328-36.

70. Pelto GH, Santos I, Gonçalves H, Victora C, Martines J, Habicht JP. Nutrition counseling training changes physician behavior and improves caregiver knowledge acquisition. J Nutr. 2004;134(2):357-62.

71. Shi $L$, Zhang J. Recent evidence of the effectiveness of educational interventions for improving complementary feeding practices in developing countries. J Trop Pediatr. 2011;57(2):91-8.

\section{Submit your next manuscript to BioMed Central and we will help you at every step:}

- We accept pre-submission inquiries

- Our selector tool helps you to find the most relevant journal

- We provide round the clock customer support

- Convenient online submission

- Thorough peer review

- Inclusion in PubMed and all major indexing services

- Maximum visibility for your research

Submit your manuscript at www.biomedcentral.com/submit
) Biomed Central 